Revista Iberoamericana, Vol. LXXIII, Núm. 221, Octubre-Diciembre 2007, 861-870

\title{
LA CIUDAD DE LOS PRODIGIOS DE EDUARDO MENDOZA FRENTE A UNA VISIÓN LATINOAMERICANA DE CIENCIA, CULTURA Y TECNOLOGÍA*
}

\author{
POR \\ JERRY HoEg \\ Pennsylvania State University
}

En La ciudad de los prodigios (1986), novela que cuenta la historia de Barcelona entre las dos Exposiciones Universales de Barcelona de 1888 y 1929, el autor catalán Eduardo Mendoza plantea una visión evolutiva de la sociedad. Efectivamente, afirma que la ciencia, la tecnología y la industria son los factores motrices del progreso social, un progreso que conduce inevitablemente al bienestar. Además, añade que oponerse a la evolución social, o sea al progreso, es un acto reaccionario, anacrónico, inútil y hasta mortal.

En el presente trabajo me propongo analizar los recursos literarios que Mendoza utiliza para armar su visión evolutiva de la sociedad y la cultura humanas, para luego contrastar esta visión con la manera de concebir las relaciones entre ciencia, tecnología y cultura propuesta por autores latinoamericanos tales como Gabriel García Márquez en Cien años de soledad (1967), Isabel Allende en La casa de los espíritus (1982), Laura Esquivel en Como agua para chocolate (1989), Rima de Vallbona en Los infiernos de la mujer y algo más... (1992) y Fernando Contreras Castro en Los Peor (1995).

En su novela, Mendoza esboza algunos principios primordiales del determinismo tal como éste se concebía en el siglo xix: “La época estaba dominada por la fe en las ciencias: no había cosa ni fenómeno que no respondiera a una causa precisa [...] lo mismo se pensaba de la conducta humana: se le buscaban razones que pudieran luego reducirse a leyes” (174). Intento argüir que esta fe en las ciencias es lo que informa la cosmovisión de toda la novela. A lo largo del libro Mendoza pretende hacer hincapié en las leyes darwinianas que rigen la sociedad humana. Según Mendoza, estrechamente vinculado con la ciencia, como si fuera la otra cara de la misma moneda, siempre se encuentra el progreso, producto del deseo innato del ser humano por el bienestar. Y como veremos, para Mendoza la fuerza motriz del progreso es la tecnología. Dejar de evolucionar, o peor aun marchar hacia atrás, es siempre mortal. En contraste nítido con esta visión, como se comentará en adelante, la percepción latinoamericana de la relación entre tecnología y progreso es precisamente la contraria. Para los autores latinoamericanos ya mencionados la ciencia y la tecnología producen una sociedad fría, mecánica y opresiva.

\footnotetext{
* Agradecimientos: El autor desea expresar su agradecimiento a Luis A. Jiménez y Beatriz RiveraBarnes por la lectura crítica de este artículo y las importantes sugerencias realizadas, las cuáles han sido muy valiosas para mejorar la presentación final.
} 
La ciudad de los prodigios empieza en el lugar de nacimiento del joven protagonista, Onofre Bouvila, un campesino ingenuo que terminará por convertirse en el hombre más rico de España. El narrador nos cuenta que Onofre había nacido en la Cataluña "agreste, sombría y brutal” (21). Esta zona era propicia a las supersticiones, "el sistema de vida era tribal” y los hombres del lugar "aún usaban pieles como parte de su indumentaria [...] tañían flautas de hueso y ejecutaban una danza que remedaba los saltos del carnero” (22). En contraste significativo, la capital regional, Bassora, "acababa de experimentar un progreso notable" (25), y la Barcelona de aquel entonces (el siglo XIX) "no había dejado de estar a la vanguardia del progreso" (25) con el primer alumbrado de gas, el primer servicio de diligencias y de ferrocarril, la primera central eléctrica, y el primer servicio de teléfono, entre otros notables ejemplos del prodigioso progreso científico e industrial.

En resumidas cuentas, a principios de la novela Mendoza recalca el contraste entre civilización y barbarie. Como comenta la voz narradora:

La Naturaleza no es sabia como dicen, sino estúpida y torpe y sobre todo cruel. Pero las generaciones han ido cambiando estas cosas de la Naturaleza: el curso de los ríos ... han domesticado a los animales y han cambiado el sistema de los árboles y de los cereales y las plantas en general: todo lo que antes era destructivo lo han hecho productivo. (264)

Cuando Onofre llega a la ciudad de Barcelona por primera vez tiene sólo trece años. Sacando provecho de cada etapa de la evolución de la ciudad -en campos tan diversos como la política, la especulación con la propiedad inmobiliaria, el contrabando de armas durante los días de la primera guerra mundial, el desarrollo de la industria cinematográficaeventualmente se convierte en el hombre más rico de España. En la lucha por la supervivencia en Barcelona, en la cual la victoria se mide en términos de dinero y poder, el éxito de Onofre demuestra más allá de cualquier duda que él es el hombre más capaz.

Ahora bien, el concepto de evolución no se restringe al caso de Onofre, sino que penetra cada rincón de la novela. Por ejemplo, en la página 329 el narrador describe la evolución de la pena de muerte en España desde la abolición de la muerte en horca, la abolición de la hopa y de la ejecución pública, las varias maneras de conducir al condenado al cadalso, etc., hasta la introducción del garrote en 1828. Asimismo rastrea la evolución del deporte desde un pasatiempo de la clase alta hasta una religión popular:

Desde que la ideología fascista se había difundido por Europa todos los gobiernos fomentaban la práctica del deporte y la asistencia masiva a las competiciones deportivas [...] trataban de imitar el imperio romano, cuyos usos tomaban por modelo anacrónico [...] con esto los políticos y pensadores contaban con mejorar la raza. (536)

También comenta la evolución de la moda (542), el nacionalismo, y varios otros temas. Lo importante es que en cada caso Mendoza vincula la evolución al progreso tecnocientífico. Por ejemplo, la evolución del concepto del tiempo es producto de la revolución industrial:

[...] donde la revolución industrial había tenido efecto había cambiado radicalmente la noción del tiempo [...] antes la puntualidad no había sido nada: ahora lo era todo. [...] Este 
reajuste no se habría podido hacer a tan gran escala de no haber venido en ayuda a los pueblos la energía eléctrica. (408-9)

De hecho, según el narrador, desde el automóvil y el avión hasta el cine, este último “un subproducto de la energía eléctrica” (385), todo progreso proviene de la evolución de los conocimientos tecnocientíficos. Vale notar que la evolución del lado creativo del cine también se basa en la evolución técnica. Mendoza rastrea las varias etapas de la evolución del cine comenzando con la fotografía, luego el cinematógrafo, y así hasta la tecnología cinematográfica de las primeras décadas del siglo xx, y a la misma vez detalla la evolución del contenido del cine, para llegar a la conclusión muy moderna de que: “iTener al público sentado, a oscuras, en silencio, como si durmiera, como si soñara: una manera de producir sueños colectivos! Este era su ideal” (410).

Para lograr dicho ideal, no únicamente la tecnología y las tramas tienen que evolucionar, sino también los actores mismos. Dicha evolución involucra cambios de nombre, domicilio, forma de pensar y hasta de los rasgos físicos de los actores a través de la cirugía cosmética. Los actores que no quieren evolucionar en seguida dejan de ser parte esencial de la industria. El no "reinventarse" continuamente equivale al fracaso. La evolución profesional, personal, y tecnológica se unen en el cine de Onofre para lograr el progreso y, a la vez, evitar la decadencia y, ulteriormente, la muerte de la industria.

Aunque a lo largo de la novela Mendoza hace hincapié en lo inevitable del progreso, también critica a las fuerzas reaccionarias que se le oponen. En la página 334, inmediatamente después de señalar la serie impresionante de los muchos éxitos científicos y tecnológicos que están por venir en el siglo xx, saca a relucir gráficamente la intransigencia de las fuerzas reaccionarias que no dejan de estorbar al progreso:

La iglesia católica no cesaba de recordar a quien quisiera oírla que el progreso no siempre seguía los derroteros marcados por la voluntad de Dios expresamente manifestada en sus apariciones e infundida al Sumo Pontífice. [...] En su aversión al progreso la Iglesia no estaba sola: la mayoría de los reyes y príncipes del mundo compartían este resquemor. (334)

Mendoza resume las fuerzas reaccionarias como "Estos pequeños grupos, integrados por aristócratas, terratenientes y algunos elementos del Ejército y el clero [que] ejercían sobre la vida política de la nación una influencia decisiva de carácter inverso” (420). El Marqués de Ut, quien en la novela representa la nobleza, es típico de este grupo apegado al pasado: “Toda innovación, aunque coincidiera con sus intereses, le horrorizaba” (420). Y porque "no se podía luchar contra el progreso sobre todo en el terreno científico” (368), al final de la novela (1929) la aristocracia sufre el mismo destino que los saurios: en 1930 el dictador Primo de Rivera presenta su renuncia al rey y se exilia a París, donde muere unos meses más tarde, el 16 de mayo de 1930, y un año más tarde el mismo Alfonso XIII abdica a la corona de España y sale al exilio. Y como sabemos, Mendoza escribió La ciudad de los prodigios durante otra transición española que de la misma forma va de saurio a democracia. 
Pero Mendoza no se conforma con proporcionarnos un solo ejemplo de la inevitabilidad del progreso y la futilidad de oponérsele. Hacia el final de la novela, Onofre, huyendo de las fuerzas conservadoras de Primo de Rivera, vuelve a su pueblo natal para esconderse mientras las autoridades lo buscan por otros lados. Inicialmente, se deja seducir por las memorias placenteras de su juventud, provocadas éstas por los sonidos, olores y paisajes de su idílico pueblo querido. Pero dentro de poco su mera presencia en la villa ocasiona la muerte del cura local y causa otras desgracias por añadidura. Esto sucede porque él ya no es del pueblo natal, sino que ha evolucionado de tal manera que ahora representa una fuerza extraña, del futuro, algo más allá y por encima de los poderes de los villanos rústicos. Su mera presencia es anatema del pasado pre-evolucionado que todavía existe en el lugar de su nacimiento. Onofre se da cuenta de que "este crimen no se habría producido nunca sin su presencia; era él quien había proporcionado al culpable la ilusión. [...] Buscando la paz había llevado al valle la discordia y la violencia. [...] No podía escapar a su destino" (476). El volver hacia atrás, en términos evolutivos, es totalmente desacertado. Al día siguiente regresa a la ciudad condal, y comienza a reconstruir una mansión que remonta al siglo anterior, pero este esfuerzo por volver hacia atrás también queda destinado al fracaso: “Aunque la restauración podía considerarse perfecta había algo inquietante en aquella copia fidelísima [...] algo demente en aquel afán por calcular una existencia anacrónica y ajena [...] todo era falso y opresivo” (481) y le preguntan cómo es que "se empeñaba ahora en recrear algo reñido con el progreso, algo que el progreso mismo había dejado atrás irremisiblemente” (447-8).

Poco después su familia rehúsa ocupar esta reliquia del pasado, dejando a Onofre solo en el mausoleo. Para librarse de la soledad, empieza a salir todas las noches: “[...] frecuentaba los antros más infames [...] buscaba la camaradería de rufianes, maleantes y putas” (483). Pensaba encontrar la felicidad de antaño, pero en realidad resulta ser simplemente un fracasado esfuerzo más por volver atrás: “creía haber reencontrado aquella Barcelona de la que había logrado elevarse pero en la que ahora creía haber sido bastante feliz. En realidad era la juventud perdida lo que añoraba” (483). Después de unos meses de esta vida contra-evolutiva es apuñalado en un prostíbulo, y por poco muere.

Otro ejemplo típico de la fatalidad de oponerse a la evolución, al cambio y al progreso tiene que ver con el famoso arquitecto catalán Antonio Gaudí i Cornet. En la novela Gaudí representa el modernismo, un movimiento retrógrado. Mendoza sitúa el noucentisme en contraste singular con el modernismo. La catedral de la Sagrada Familia, "aquella obra anacrónica e imposible” (507), es el eje principal del debate en cuestión. En otra instancia narrativa captamos que el modernismo "tenía los ojos en el pasado, con preferencia en la Edad Media [...] idealista y romántico” (506), mientras el noucentisme tenía los ojos "puestos en el futuro" y era "materialista y escéptico". En la novela las últimas palabras de Gaudí son: "El progreso y yo estamos en guerra” (507) y acto seguido muere, irónicamente, “atropellado por un tranvía eléctrico”. Abundan otros ejemplos de esta índole, como se ve en el caso del padre de Onofre, quien intentaba evolucionar y cuando no pudo sufrió una muerte miserable aunque merecida según la teoría darwiniana, pero con la historia de Gaudí la moraleja ya queda cristalizada para el lector. 
Asimismo vale comentar la naturaleza de los científicos que desempeñan papeles tan significativos en la novela. Son tres: Faustino Zuckerman, Santiago Belltall y un ingeniero militar prusiano, cuyo nombre no se menciona en el texto. El primero, Zuckerman, "un hombre de origen centroeuropeo” (423), dirige el proyecto cinematográfico de Onofre. Es alcohólico y muy exigente, un tirano "dado a sufrir ataques súbitos de cólera incontrolables” (424), pero este director maniático logra hacer evolucionar el cine catalán desde una simple documentación hecha a pesar de un "abismal atraso tecnológico" (424) hasta un medio moderno y tecnológicamente sofisticado que conmovió profundamente al público mientras proyectaba "las ilusiones y los terrores de la humanidad" (425).

Santiago Belltall, un inventor catalán con apellido y orígenes ingleses, es un científico enloquecido también: "tenía el aspecto desnutrido y fatigado del hombre que ha dejado de comer y de dormir por causa de una obsesión [...] aparentaba el doble de su propia edad” (366). La obsesión de Belltall es el helicóptero, obsesión que lleva a cabo por medio del dinero de Onofre y los conocimientos técnicos del ingeniero prusiano, quien tiene sus propias excentricidades. Gracias al prusiano "las ideas disparatadas de Santiago Belltall habían evolucionado hasta convertirse en algo científico” (565).

Lo que cobra suma importancia en la obra es el hecho de que ninguno de los científicos que desempeñan papeles importantes en el progreso tecnocientífico es español. Es decir, que el progreso proviene de los países protestantes e industrializados, productos del iluminismo y la revolución industrial. Dada la elección planteada por Unamuno entre europeizarse o africanizarse a la antigua en Sobre la europeización (1906), parece bastante obvio que Mendoza vota por el europeizarse y por el progreso, por la evolución no únicamente inevitable sino también deseable. Cabe mencionar que La ciudad de los prodigios fue la novela más leída en España en 1986, de hecho una de las más leídas de la década, y que fue trasladada a la pantalla donde encontró un éxito comercial enorme también. En vista de la popularidad tanto de la novela como de la película entre el público en España, parece lógico concluir que la mayoría de los españoles compartían la opinión del autor catalán en cuanto a la necesidad de europeizarse, sobre todo después de los muchos años de retraso bajo Franco.

Frente a esta perspectiva española sobre la ciencia y la tecnología, podemos contrastar el punto de vista latinoamericano tal como éste se plantea en la literatura del mismo período cronológico. En la segunda mitad del siglo xx ha surgido en la literatura latinoamericana una reacción bastante fuerte en contra de la ciencia y la tecnología, y a favor de un mundo edénico, pretecnológico. El proyecto antitecnológico rechaza el concepto del progreso infinito posibilitado por medio de la ciencia y la tecnología extranjeras. En Cien años de soledad, Gabriel García Márquez demuestra que la cultura racio-productiva y tecnológica del explícitamente norteamericano Mr. Herbert y la compañía bananera (United Fruit Company) es una catástrofe en la América Latina. La llegada de Mr. Herbert y su tecnología extranjera trae consigo una serie de desastres: la destrucción del medio ambiente, matanzas masivas de obreros e inundaciones de proporciones bíblicas.

En La casa de los espíritus Isabel Allende saca a relucir el tema de la contra-finalidad de la razón inherente en el ordenamiento racional del mundo. Mr. Herbert de Cien años de soledad es ahora el "tiny gringo" experto Mr. Brown, y la plaga bananera ya es la plaga 
de hormigas en el rancho de las Tres Marías, donde la tecnología norteamericana de Mr. Brown contiende contra los conocimientos locales de Pedro Segundo García. El conocimiento no tecnológico de García gana al nivel local de las Tres Marías, pero al nivel nacional la tecnología no-nativa, de tipo racio-militar, triunfa con el coup d'etat que reemplaza a Allende por Pinochet y produce abiertamente un desastre nacional.

En Como agua para chocolate, el gringo científico, el doctor John Brown de Harvard, sirve de contrapunteo racional y masculino a la emoción femenina de Tita, otro caso del conocimiento tecnocientífico versus los remedios caseros, o sea los conocimientos locales. Dicho sea de paso, los remedios caseros le vienen a Tita a través de la indígena Nacha, muy a menudo por medio de comunicaciones inexplicables desde el punto de vista científico. Según Alfonso Arau, el director de la versión cinematográfica de Como agua para chocolate, "The heroine, Tita, and the maid Nacha represent intuition, passion, sentiment associated with the female mentality. And this film was about the superiority of intuition over reason" (Elias).

El mismo tema de emoción versus razón también reaparece en la producción novelística costarricense. En Los Peor, por ejemplo, Fernando Contreras Castro opone un gringo médico, un tal doctor Evans, a un misterioso ex jesuita llamado Jerónimo Peor. La batalla entre ellos gira en torno a una paciente que ha sido dañado por pesticidas, o sea por la tecnología gringa importada. El doctor Evans aconseja un curso de tratamiento, pero a la paciente Jerónimo "le prohibió tomar los medicamentos de Evans. [...] No en vano Jerónimo había convivido con las indígenas suramericanas tanto tiempo [...] había aprendido a curar con hierbas” (23). En este caso y a lo largo de la novela, los conocimientos precientíficos de Jerónimo resultan mejores que los tecnocientíficos del gringo Evans.

En Los infiernos de la mujer y algo más... (1992) la costarricense Rima de Vallbona hace hincapié en lo malvado de la ciencia y la tecnología norteamericanas. En "El corrector de la historia”, leemos que la protagonista, "que despotricaba tanto contra el materialismo automático del siglo xx [...] sintió vergüenza de haber llegado a depender de un objeto” (31). El objeto es una camioneta que simboliza la presencia de su vecino, un hombre que

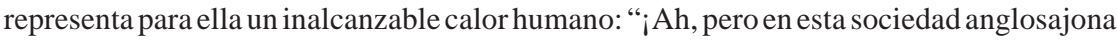
yo no tengo derecho a buscar tal compañía!, aquí nosotros, los de sangre humana, somos unos histéricos [...] nuestra pequeñez hispánica se hace añicos contra el concreto, hierro y metal del temple gringo" (33). En este pasaje otra vez notamos que la imagen tradicional del racional, industrializado y frío vecino del norte se contrasta con la imagen del emocional, antitecnológico y muy humano vecino del sur.

En otro cuento proveniente de la misma colección, "Los males venideros", Mr. Congos, representante de la TWD Business Systems Inc., le trae a la protagonista "la culminación de la tecnología electrónica” (40), una computadora. Al poco tiempo, la computadora cobra vida propia y se convierte en "monstruo electrónico”, un monstruo que empieza a escribir la historia de la protagonista, con un "horripilante final de sangre y muerte” (43) perpetrado por “un hombrazo oscuro con sádica sonrisa” (45). Esta vez, en un final escrito por la tecnología misma, o sea la computadora, no hay ningún calor humano y la protagonista muere sin poder luchar contra el remate tecnológico. En 
definitiva, según el monstruo, “en estos tiempos de tecnología [...] el progreso vomita una recua de delincuentes viciosos” (44), y no hay donde esconderse.

Los científicos descritos por Mendoza y los descritos por los autores latinoamericanos ya mencionados son productos del iluminismo y de la revolución industrial, y por ende de la evolución de la sociedad humana. Son símbolos de los avances científicos y tecnológicos que suministran el progreso a las sociedades occidentales, al mundo moderno. Lo interesante es que, en función del contexto social de los dos lados del Atlántico, son valorados o menospreciados por desempeñar la misma función social. De ahí que se pueda notar que la literatura de ambos lados está fuertemente vinculada con la ciencia. Ambas muestras literarias pretenden controlar el discurso de la ciencia, ambas intentan apoyar o contrarrestar las corrientes científicas de su época. Simultáneamente, la ciencia misma desempeña un papel de suma importancia en la literatura ya que los autores antes mencionados se ven obligados en su producción creativa a abogar a favor o en contra de la ciencia. Es decir, que ambos discursos, el tecnocientífico y el humanístico, se informan mutuamente.

En efecto, en los ejemplos latinoamericanos que hemos venido comentando, todos de una índole literaria que la crítica muy a menudo ha denominado realismo mágico, la tecnología se ve como una herramienta, cuando no como un arma, de la clase dirigente. Se percibe una estrecha vinculación entre dominación y tecnología, y por lo tanto la tecnociencia se considera un yugo del cual librarse. En cambio, en la España de la transición, después del aislamiento y del retraso intelectual del franquismo, la tecnología proveniente de la Europa moderna y próspera parece ser la clave de la libertad tanto económica como espiritual. La ciencia, la tecnología y el concomitante progreso social y económico parecen ser los antídotos a la dominación del pueblo por parte del Estado, del ejército, de la iglesia y de las clases dirigentes.

Ahora bien, al mencionar la libertad espiritual cabe añadir que ambas corrientes literarias contienen fuertes componentes espirituales. De hecho, la relación entre la ciencia y el espiritualismo -o la religión, que es el espiritualismo codificado- tiene una larga historia. La fe en lo que no se puede ver es un arma tradicional de la cual la humanidad se ha servido históricamente para controlar el medio circundante, sea este medio ambiente sicológico o físico. Por lo menos desde el paleolítico alto, hace unos cuarenta mil años, el ser humano se ha dedicado a desarrollar tanto la tecnología como el espiritualismo para dominar su mundo. Los primeros entierros de cadáveres humanos acompañados de ritos funerarios empiezan en este período: el lago Mungo en Australia hace cuarenta y tres mil años (Gillespie) y Sungir en Rusia hace aproximadamente veinticuatro mil años (Pettit \& Bader) entre otros, y unas pinturas simbólicas para controlar la caza se hacen en las cuevas de Chavet hace treinta mil años, en las de Lascaux hace diecisiete mil años, y en las Fontde-Gaume y Altamira un poco después. Y finalmente, hace unos veintiocho mil años, unas pequeñas figuras de Venus, diosa de la fecundidad, comienzan a aparecer desde Europa occidental hasta Siberia.

Estrechamente conectados con estos discursos simbólicos, cabe mencionar que las primordiales obras de teatro tenían temas religiosos relacionados con el esfuerzo por controlar la naturaleza, o sea cambios climáticos, la cosecha, etc.: el Memphite Drama y el Abydos Passion Play, ambos de Egipto alrededor de 2550 a.C., tratan la muerte y 
resurrección de Osiris, dios de la fecundidad de la naturaleza. En el mismo momento se presentan obras parecidas en Sumeria, Babilonia, Canaán y otras civilizaciones agrícolas tempranas (Gaster). Y no es coincidencia que la alquimia, precursora de la química y las ciencias modernas, tenga sus raíces en el Egipto helenístico del siglo Iv, sobre todo en Alejandría, donde una confluencia de astrología babiloniana, tradiciones mágicas caldeas y secretos metalúrgicos de los sacerdotes de Isis se asocian con los primeros intentos de transmutar los metales bases en oro. En la medida en que el poder de la tecnología ha venido creciendo, desde Galileo pero sobre todo desde el siglo XIX, la función social de controlar la tecnología ha pasado de la religión a la ciencia, es decir de la creencia en lo que no se puede ver a la creencia en lo que se puede ver y comprobar, entre los sectores industrializados del mundo, siempre y cuando les sirva de ventaja. Entre los sectores demográficos que no han sacado provecho de los avances tecnocientíficos, y que muy a menudo han sufrido a causa de ellos -es decir los sectores de bajos ingresos en cualquier país del mundo-, la fe, la religión y el espiritualismo, o sea la creencia en lo que no se puede ver, han cobrado un vigor fundamental.

En La ciudad de los prodigios Mendoza hace patente la relación entre ciencia, tecnología y espiritualismo al describir los últimos fines del proyecto cinematográfico de Onofre Bouvila quien “se consideraba un nuevo Mesías” (373). Onofre pretende unir la tecnología y el espiritualismo a través del cine para proporcionarle a las masas un nuevo sistema de creencias, y así asegurarse un control total. En otra instancia narrativa, el narrador explica “Julio César, Napoleón, Felipe II [...] Todos ellos habían sufrido la derrota y el fracaso más humillantes; habían confiado en la fuerza de las armas y habían desdeñado la fuerza espiritual [...] pero Onofre Bouvila reharía esta trama a partir de una simiente espiritual [...]" (393). A saber: "reemplazar la religión ancestral por el cinematógrafo" (447). Dentro del texto el plan de Onofre fracasa, pero el éxito de la novela misma y su versión cinematográfica deja abierta la cuestión de la posible instauración de creencias por parte de los medios de comunicación y otras tecnologías. A modo de premonición, al final de la obra Onofre sube al cielo en helicóptero como un Jesucristo tecnológico. No cabe duda de que la España europea está completamente de acuerdo con el mensaje de progreso y evolución esbozado en La ciudad de los prodigios. Nos referimos a la España europea porque hay sectores islámicos fundamentalistas (Canales y Montánchez) que pretenden volver hacia atrás en la vana esperanza de encontrar el bienestar en un pasado imaginario, pues históricamente el mismo debate entre fe y ciencia ha existido en el mundo islamista, incluso durante su mando en la Península Ibérica.

Por otro lado, tampoco cabe duda de que el realismo mágico ha tenido influencia profunda en cuanto al espiritualismo se refiere, particularmente en las Américas. Podemos citar el debate epistemológico simbolizado por la literatura denominada testimonio, sobre todo el célebre caso de Rigoberta Menchú y David Stahl. En términos historiográficos, como ha detallado Roberto González Echevarría, en las letras latinoamericanas siempre ha habido una oscilación entre la acogida y el rechazo del discurso científico proveniente de los países industrializados. De hecho, la historia de la literatura universal revela la oscilación por parte de la sociedad entre amor o desdén por la ciencia y los científicos. En Canon's Yeoman's Tale (1387) Geoffrey Chaucer distingue entre buena y mala alquimia, 
y a través de los siglos el doctor Fausto se pinta ora como charlatán ora como científico serio y digno y el doctor Frankenstein de Mary Shelly es emblemático del odio contra el progreso científico.

Conviene agregar que explicar dicha oscilación es una de las cuestiones más urgentes para los estudios sobre las relaciones entre las humanidades, la tecnología y las ciencias. Al mismo tiempo es importante notar que ambos discursos, el científico y el humanístico, son dos caras de la misma moneda. No es sorprendente reconocer que la tecnología se convierte en el instrumento que ambos discursos utilizan para transformar la naturaleza según las necesidades de la sociedad. La dirección de las investigaciones científicas se controla a través de la sociedad, y la sociedad determina esta dirección no por medio de cavilaciones racionales y lógicas, sino por narrativas sociales que pocas veces son razonables a nivel manifiesto, pero que sí lo son a nivel del subconsciente social. Es una relación de retroalimentación mutua. En función de la relación de la sociedad con el uso o abuso de los recursos naturales, la sociedad produce narrativas sociales que determinan lo que la ciencia va a investigar, y cómo los avances así producidos llegarán a convertirse en usos y poderes tecnológicos. En otras palabras, el discurso de la ciencia y de la tecnología aparece como un texto social. La sociedad convierte los datos científicos, verídicos o no, en una narrativa que sirve funciones sociales y cuya eficacia no proviene de lo fehaciente de las observaciones científicas. La fe se hace de otras maneras.

Conviene también darnos cuenta del hecho de que las relaciones sociales pertenecen a dos categorías. En primer lugar hay narrativas que tratan las relaciones intrasociales entre los seres humanos: el amor, el odio, las jerarquías sociales, el deseo, etc. Por consiguiente, existen muchas narrativas en las cuales no entran directamente consideraciones ni de la ciencia ni de la tecnología. Estas relaciones intrasociales han sido tradicionalmente el enfoque de la crítica literaria. Sin embargo, hay otra categoría de narrativa social que trata las relaciones entre la sociedad y la naturaleza, o sea, las relaciones extrasociales. Frecuentemente las dos categorías aparecen en la misma obra. El problema surge al confundir las dos categorías, o simplemente hacer caso omiso de la segunda. Obviamente, van a surgir errores de categorización si tratamos las relaciones entre sociedad y el medio circundante sin tomar en cuenta los discursos científicos y tecnológicos que las mediatizan. Los discursos culturales extrasociales se engendran de las necesidades impuestas sobre la sociedad por parte de la naturaleza. Como hemos venido comentando, desde las producciones culturales primordiales el intento de la narrativa social ha sido la sobrevivencia de la humanidad. Una de las funciones del mito o del rito, de la historia o de las historias, siempre ha sido la de mediatizar la relación entre sociedad y medioambiente (Rappaport). Y es aquí donde el análisis de las relaciones entre literatura, ciencia y tecnología demuestra una vez más la necesidad de considerar el factor material en la construcción del discurso sociocultural. La narrativa sirve para mediatizar tanto las relaciones entre seres humanos como las relaciones entre sociedad y medio circundante.

A modo de conclusión, simplemente queremos observar que la crítica que tiene presentes las relaciones entre discurso científico y discurso humanístico tendrá la oportunidad de esclarecer una categoría importante de la narrativa cultural que hasta la actualidad a veces ha sufrido interpretaciones empobrecidas por falta de una comprensión de la naturaleza distinta de esta otra categoría de relaciones. Se debe tener siempre presente 
que la narrativa sirve para mantenernos en una relación estable tanto con el prójimo como con lo próximo, que también de pan vive el hombre.

\section{Bibliografía}

Allende, Isabel. The House of the Spirits. Magda Bogin, trad. Nueva York: Bantam, 1986. Canales, Pedro y Enrique Montánchez. En el nombre de Alá. Barcelona: Planeta, 2002. Contreras Castro, Fernando. Los Peor. San José: Farben, 1995.

Elias, Thomas D. "The Miracle Worker. How Alfonso Arau's 'Water for Chocolate' Dream Came True”. Chicago Tribune (6 de marzo de 1994), sec. 13: 19.

Esquivel, Laura. Como agua para chocolate: novela de entregas mensuales con recetas, amores y remedios caseros. México: Planeta, 1990.

García Márquez, Gabriel. One Hundred Years of Solitude. Gregory Rabassa, trad. Nueva York: Bard, 1971.

Gaster, Theodor. Thespis: Ritual, Myth, and Drama in the Near East. Garden City: Doubleday, 1961.

González Echevarría, Roberto. Myth and Archive: A Theory of Latin American Literature. Nueva York: Cambridge UP, 1990.

Gillespie, R. “Alternative Time Scales: A Critical Review of Willandra Lakes Dating”. Archaeology in Oceania 33/3 (1998): 169-82.

Mendoza, Eduardo. La ciudad de los prodigios. Barcelona: Seix Barral, 1986.

Pettitt, P. B. y N. O. Bader. "Direct AMS Radiocarbon Dates for the Sungir Mid-Upper Paleolithic Burials”. Antiquity 74 (2000): 269.

Rappaport, Roy A. Pigs for the Ancestors: Ritual in the Ecology of a New Guinea People. New Haven: Yale UP, 1969.

Vallbona, Rima de. Los infiernos de la mujer y algo más... Madrid: Torremozas, 1992. 